\title{
Impact of skeletal muscle mass in patients with unresectable gastric cancer who received palliative first-line chemotherapy based on 5 -fluorouracil
}

Tomoyuki Matsunaga ${ }^{1 *}$, Hiroaki Saito², Wataru Miyauchi', Yuji Shishido ${ }^{1}$, Kozo Miyatani', Masaki Morimoto ${ }^{1}$, Yuki Murakami ${ }^{1}$, Takehiko Hanaki', Kyoichi Kihara', Manabu Yamamoto', Naruo Tokuyasu', Shuichi Takano', Teruhisa Sakamoto ${ }^{1}$, Toshimichi Hasegawa ${ }^{1}$ and Yoshiyuki Fujiwara ${ }^{1}$

\begin{abstract}
Background: The mortality rate of patients with unresectable gastric cancer (UGC) has decreased with the development of chemotherapies and surgical techniques. However, the survival rate remains low. We retrospectively examined the prognostic significance of the pretreatment skeletal muscle mass index (SMI) and nutritional and inflammatory factors in patients with UGC.

Methods: This study included 83 patients diagnosed with UGC at Tottori University Hospital who received palliative chemotherapy based on 5-fluorouracil. Pretreatment computed tomography (CT) measured overall skeletal muscle mass (SMM) and cross-sectional SMM at the third lumbar vertebra (L3). We focused on the neutrophil-tolymphocyte ratio (NLR), C-reactive protein-to-albumin ratio (CAR), prognostic nutritional index (PNI), and platelet-tolymphocyte ratio (PLR) as nutritional and inflammatory factors.

Results: Receiver operating characteristic curve analysis was performed for median survival time (MST) after palliative chemotherapy. SMls for males and females $\left(43.9 \mathrm{~cm}^{2} / \mathrm{m}^{2}\right.$ and $34.7 \mathrm{~cm}^{2} / \mathrm{m}^{2}$, respectively) were the cutoff values, and patients were divided into high (SMI High; $n=41$ ) and low SMI groups (SMI $\left.{ }^{\text {Low }} ; n=42\right)$. Body mass index (BMI) was significantly higher in patients in the SMI High group than in the SML ${ }^{\text {Low }}$ group $(p<0.001)$. The number of patients who received third-line chemotherapy was significantly higher in the SMI ${ }^{\text {High }}$ group than in the SMI ${ }^{\text {Low }}$ group $(p=0.037)$. The MST was significantly higher in the SMI High group than in the SMI ${ }^{\text {Low }}$ group (17.3 vs. 13.8 months; $p=0.008)$. The incidence of grade 3 or 4 side effects was significantly higher in patients with SMI ${ }^{\text {Low }}$ UGC $(p=0.028)$. NLR was significantly higher in patients with $S M^{L}{ }^{\text {Low }}$ than it was in those with SMIligh $(p=0.047)$. In the univariate analysis, performance status, SMI, histological type, lines of chemotherapy, and NLR were prognostic indicators. The multivariate analysis identified SMI $(p=0.037), \operatorname{NLR}(p=0.002)$, and lines of chemotherapy $(p<0.001)$ as independent prognostic factors.
\end{abstract}

\footnotetext{
* Correspondence: matut0m0@tottori-u.ac.jp

'Department of Surgery, Division of Gastrointestinal and Pediatric Surgery,

School of Medicine, Tottori University Faculty of Medicine, 36-1 Nishi-cho,

Yonago 683-8504, Japan

Full list of author information is available at the end of the article
}

C C The Author(s). 2021 Open Access This article is licensed under a Creative Commons Attribution 4.0 International License, which permits use, sharing, adaptation, distribution and reproduction in any medium or format, as long as you give appropriate credit to the original author(s) and the source, provide a link to the Creative Commons licence, and indicate if changes were made. The images or other third party material in this article are included in the article's Creative Commons licence, unless indicated otherwise in a credit line to the material. If material is not included in the article's Creative Commons licence and your intended use is not permitted by statutory regulation or exceeds the permitted use, you will need to obtain permission directly from the copyright holder. To view a copy of this licence, visit http://creativecommons.org/licenses/by/4.0/ The Creative Commons Public Domain Dedication waiver (http://creativecommons.org/publicdomain/zero/1.0/) applies to the data made available in this article, unless otherwise stated in a credit line to the data. 
Conclusions: The SMI ${ }^{\text {Low }}$ group had significantly more grade 3 or 4 side effects, were related to high NLR, and had a significantly worse prognosis than the SMI ${ }^{\text {High }}$ group.

Trial registration: Retrospectively registerd.

Keywords: Gastric cancer, Chemotherapy, Skeletal muscle mass

\section{Introduction}

Gastric cancer is the fifth most common and third leading cause of cancer in the world [1]. The main strategy for gastric cancer is gastrectomy. However, the prognosis is poor because recurrence is common after gastrectomy, and patients with gastric cancer are often diagnosed with metastasis to other organs $[2,3]$. The main strategy for unresectable gastric cancer (UGC) is chemotherapy. The mortality rate decreases with the development of chemotherapies and surgical techniques; however, the survival rate remains low [4, 5]. Many combination chemotherapy regimens have been studied in randomized trials. Five-fluorouracil (5-FU) is a key drug used in combination with other drugs for first-line chemotherapy in patients with UGC [6-8].

Sarcopenia is a disease defined by loss of skeletal muscle mass (SMM) and function. Its prognosis has been reported to be poor in various cancers, including gastric cancer $[9,10]$. In advanced gastric cancer with metastasis to another organ, most patients suffer from poor dietary intake, resulting in inadequate nutrition. In patients with recurrent gastric cancer, gastrectomy reduces the stomach's capacity to digest, decreasing meal intake and resulting in weight and SMM loss. These findings suggest that patients with UGC already have reduced SMM at the time of diagnosis. Sarcopenia may influence chemotherapy pharmacokinetics, which could be associated with the adverse effects of chemotherapy in several cancers $[11,12]$. However, there are no reports of an association between SMM and side effects or prognosis in patients with UGC treated with 5-FU based chemotherapy. Furthermore, the reason for the relationship between sarcopenia and poor cancer prognosis remains unclear. On the other hand, nutritional status or inflammation could be a prognostic factor for patients with cancer.

Recently, the relationship between nutrition-based and inflammation-based markers and prognosis has also been reported in various cancers, including gastric cancer [13, 14]. Many inflammatory markers that can be used to predict prognosis have been reported, such as the C-reactive protein (CRP)-to-albumin ratio (CAR), neutrophil-to-lymphocyte ratio (NLR), platelet-to-lymphocyte ratio (PLR), and the prognostic nutritional index (PNI). However, the relationship between sarcopenia and inflammatory markers is still unclear.
This study investigated the relationship between SMM, chemotherapy side effects, and prognosis in patients with UGC. We also investigated the relationship between SMM and nutritional and inflammatory markers.

\section{Patients and methods \\ Patients}

Between January 2008 and December 2019, 47 patients were pathologically diagnosed with unresectable advanced gastric cancer, and 67 patients developed recurrence after undergoing curative gastrectomy for gastric cancer at Tottori University Hospital. Of those 114 patients, 83 received palliative first-line chemotherapy based on 5-fluorouracil (5-FU) and were analyzed in this study. The Japanese gastric cancer treatment guidelines were used to determine clinicopathological findings [7]. Clinical data, such as age, sex, Eastern Cooperative Oncology Group Performance Status (ECOG PS), and type of metastatic site at the time of diagnosis of unresectable advanced gastric cancer or recurrence, were collected from electronic medical records. The follow-up schedule of patients who underwent curative gastrectomy was every three months to check for recurrence by performing blood tests and physical examination. After the operation, CT was performed at least every six months. The causes of death were examined from clinical records. CT and positron emission tomography CT were used to detect unresectable lesion or recurrence patterns. Overall survival (OS) was defined as the time from initiation of first-line chemotherapy until death from any cause or the last follow-up.

\section{Definition of skeletal muscle mass index}

All patients were diagnosed as having UGC by CT, and the CT was used as pretreatment CT to measure SMM. All patients received first-line chemotherapy within 3 weeks of receiving the pretreatment CT. Pretreatment CT was performed to measure SMM, and a threedimensional medical image analysis system (SYNAPSE VINCENT, FujiFilm Corporation, Tokyo, Japan) was used to measure the cross-sectional SMM at the level of L3 [15]. The areas covered by SMM were calculated from pixels in the density range of -29 to +150 Hounsfield Units, which included muscle and intra-abdominal organs but excluded bone and fat [16]. The L3 region 
comprised the psoas, paraspinal, and abdominal wall muscles (Fig. 1). The skeletal muscle area in a single abdominal image was proportional to the whole-body muscle mass [17]. SMI was defined as the muscle area normalized by the square of the height $\left(\mathrm{m}^{2}\right)[18]$.

\section{Details of first-line chemotherapy}

The standard first-line palliative systemic chemotherapy was based on the 5-FU regimen administered per the gastric cancer treatment guidelines for each decade [19, 20]. At the physician's discretion, a single agent was used in patients with an ECOG PS of $\geq 2$, those older than 80 years, or those who refused combined chemotherapy. Monotherapy was administered in 13 patients, and combination chemotherapy was administered in 70 patients in this study. The monotherapy regimen was the S-1 regimen, and the combination chemotherapy regimens were as follows: (1) combined S- $1+$ cisplatin $(n=19),(2)$ combined $\mathrm{S}-1+$ paclitaxel + intraperitoneally infused paclitaxel $(n=15)$, (3) combined S- $1+$ oxaliplatin $(n=$ 13), (4) combined S-1 + docetaxel $(n=10)$, (5) combined capecitabine + oxaliplatin $(n=5)$, (6) combined capecitabine + cisplatin $(n=3)$, (7) combined capecitabine + trastuzumab $(\mathrm{n}=3)$, and (8) combined S-1 + cisplatin + docetaxel $(n=2)$. Of the 83 patients who underwent chemotherapy for UGC, 67 patients (80.7\%) received second-line chemotherapy, and 41 patients $(49.4 \%)$ received third-line chemotherapy.

\section{Definition of side effects}

The National Cancer Institute Common Toxicity Criteria version 4.0 was used to grade the chemotherapy side effects [21]. We examined the side effects observed

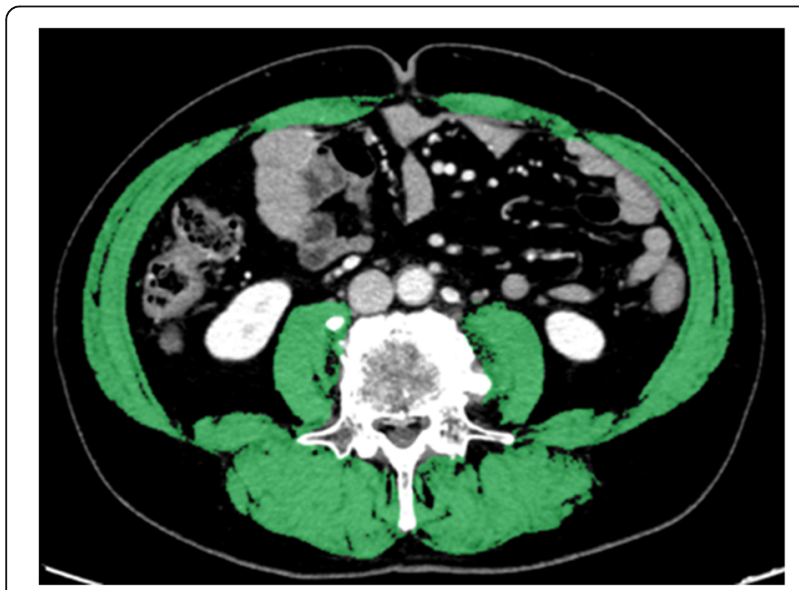

Fig. 1 Measurement of skeletal muscle mass in patients with unresectable gastric cancer. Axial computed tomography slice of the third lumbar vertebra. Green areas indicate skeletal muscle mass. Abbreviations: SMM, skeletal muscle mass; UGC, unresectable gastric cancer in the first three cycles of first-line chemotherapy. A higher grade was used in patients with multiple side effects. We focused on hematologic toxicity, febrile neutropenia (FN), and gastrointestinal toxicity.

\section{Definition of nutrition-based and inflammation-based factors}

The nutrition- and inflammation-based prognostic scores in this study were the CAR, which was the CRP level divided by the albumin level (CRP measured in $\mathrm{mg} / \mathrm{L}$, and albumin measured in $\mathrm{g} / \mathrm{L}$ ) [22]; the NLR [23]; the PNI, which was calculated by the formula $10 \times$ albu$\min (\mathrm{g} / \mathrm{dL})+0.005 \times$ lymphocyte count $/ \mu \mathrm{L}[24]$; and the PLR [13]. All indicators involved in calculating nutritionand inflammation-based prognostic scores were measured within seven days before chemotherapy. All measurements were recorded from the same blood sample.

\section{Statistical analysis}

The Mann-Whitney U test was used to compare continuous variables. Categorical variables were compared by the Fisher's exact test or $\chi^{2}$ test. The Kaplan-Meier method was used to calculate survival curves, and differences between survival curves were examined using the log-rank test. The Cox's proportional hazards model was used to perform the univariate and multivariate analyses of OS prognostic factors. $P<0.05$ was considered significant. SPSS software (SPSS for Windows version 24; IBM Corp., Armonk, NY, USA) was used for all statistical analyses.

\section{Results}

Patient characteristics and prognosis in patients with UGC Table 1 summarizes the characteristics of patients included in the current study. Overall, there were 61 (73.4\%) males and 22 (26.6\%) females, and their average age was $65.4 \pm 12.4$ years (range $32-84$ ). The ECOG PS status of 41,38 , and 4 patients was 0,1 , and 2 , respectively. The average SMI was $42.8 \pm 7.7 \mathrm{~cm}^{2} / \mathrm{m}^{2}$, and the average BMI was $20.0 \pm 3.8 \mathrm{~cm}^{2} / \mathrm{m}^{2}$. The cause of the unresectable condition was advanced disease in 39 cases and recurrent disease in 44 cases. The most common metastatic site was the peritoneum, followed by lymph nodes and hematogenous metastasis. Regarding histology, 38 patients had a differentiated-type carcinoma, and 45 had an undifferentiated-type carcinoma.

The median survival rate (MST) was 16.0 months in patients with UGC (Fig. 2). The receiver operating curve analysis for the 16.0 months OS for each sex indicated that the optimal cutoff of the SMI was $45.1 \mathrm{~cm}^{2} / \mathrm{m}^{2}$ (males) and $34.5 \mathrm{~cm}^{2} / \mathrm{m}^{2}$ (females) (Fig. 3). Based on the optimal cutoff, patients were divided into a high SMI group (SMI ${ }^{\text {High }}$ group; $n=41$ ) and a low SMI group (SMI ${ }^{\text {Low }}$ group; $n=42$ ). Table 1 shows the relationships 
Table 1 Clinicopathological characteristics of patients with SMI ${ }^{\text {High }}$ and SMI ${ }^{\text {Low }}$ UGC

\begin{tabular}{|c|c|c|c|c|}
\hline & All patients $(n=83)$ & $\mathrm{SMI}^{\mathrm{High}}(n=41)$ & SMI $^{\text {Low }}(n=42)$ & $p$ value \\
\hline Age (years) & $65.4 \pm 12.4$ & $64.9 \pm 14.5$ & $67.9 \pm 9.2$ & 0.176 \\
\hline Sex & & & & 0.119 \\
\hline Male & $61(73.5)$ & $27(65.9)$ & $34(81.0)$ & \\
\hline Female & $22(26.5)$ & $14(34.1)$ & $8(19.0)$ & \\
\hline ECOG PS (0/1/2) & & & & 0.209 \\
\hline 0 & $41(49.4)$ & $24(58.5)$ & $17(40.5)$ & \\
\hline 1 & $38(45.8)$ & $16(39.0)$ & $22(52.4)$ & \\
\hline 2 & $4(4.8)$ & $1(2.5)$ & $3(7.1)$ & \\
\hline BMI & $20.0 \pm 3.8$ & $21.5 \pm 4.3$ & $18.6 \pm 2.5$ & $<0.001$ \\
\hline SMl & $42.8 \pm 7.7$ & $47.4 \pm 7.3$ & $38.2 \pm 5.0$ & $<0.001$ \\
\hline Unresectable cause & & & & 0.907 \\
\hline Advanced cases & $39(47.0)$ & $19(46.3)$ & $20(47.6)$ & \\
\hline Recurrent cases & $44(53.0)$ & $22(53.7)$ & $22(52.4)$ & \\
\hline Histologic type & & & & 0.222 \\
\hline Differentiated & $38(45.8)$ & $16(39.0)$ & $22(52.4)$ & \\
\hline Undifferentiated & $45(54.2)$ & $25(61.0)$ & $20(47.6)$ & \\
\hline Peritoneum metastases & & & & 0.903 \\
\hline Positive & $37(44.6)$ & $18(43.9)$ & $19(45.2)$ & \\
\hline Negative & $46(55.4)$ & $23(56.1)$ & $23(54.8)$ & \\
\hline Lymph node metastases & & & & 0.898 \\
\hline Positive & $35(42.2)$ & $17(41.5)$ & $18(42.9)$ & \\
\hline Negative & $48(57.8)$ & $24(58.5)$ & $24(57.1)$ & \\
\hline Hematogenous metastases & & & & 0.867 \\
\hline Positive & $25(30.1)$ & $12(29.3)$ & $13(31.0)$ & \\
\hline Negative & $58(69.9)$ & $29(70.7)$ & $29(69.0)$ & \\
\hline Lines of chemotherapy & & & & 0.289 \\
\hline$<2$ nd line & $16(19.3)$ & $6(14.6)$ & $10(23.8)$ & \\
\hline$\geqq 2$ nd line & $67(80.7)$ & $35(85.4)$ & $32(76.2)$ & \\
\hline \multicolumn{5}{|l|}{ Lines of chemotherapy } \\
\hline$<3$ rd line & $42(50.6)$ & $16(39.0)$ & $26(61.9)$ & 0.037 \\
\hline$\geqq 3$ rd line & $41(49.4)$ & $25(61.0)$ & $16(38.1)$ & \\
\hline
\end{tabular}

Data are presented as mean \pm standard deviation or number (percentage) of patients

BMI, body mass index; ECOG PS, Eastern Cooperative Oncology Group performance status; SMI, skeletal muscle mass; SMI ${ }^{\text {High }}$, high skeletal muscle mass; SMI ${ }^{\text {Low }}$

low skeletal muscle mass; UGC, unresectable gastric cancer

between SMI and clinicopathological variables of the patients. BMI was significantly higher in patients in the $\mathrm{SMI}^{\text {High }}$ group than in the $\mathrm{SMI}^{\mathrm{Low}}$ group $(P<$ 0.001). The number of patients who received third-line chemotherapy was significantly higher in the SMI ${ }^{\mathrm{High}}$ group than in the $\mathrm{SMI}^{\mathrm{Low}}$ group $(P=0.037)$. No significant differences were observed regarding age, gender, ECOG PS, unresectable cause, histologic type, metastatic site, and the number of patients who received secondline chemotherapy. The MST was significantly higher in the $\mathrm{SMI}^{\text {High }}$ group (17.3 vs. 13.8 months; $P=0.008$, Fig. 4).

\section{Details of first-line chemotherapy and side effects}

Table 2 presents the details of SMI and first-line chemotherapy. The SMI ${ }^{\mathrm{Low}}$ group tended to include more patients treated with monotherapy than the $\mathrm{SMI}^{\mathrm{High}}$ group $(P=0.144)$. Table 3 presents the details of the side effects of each regimen used in first-line chemotherapy, and gastrointestinal toxicities according to each symptom are also described. Table 4 presents the details of SMI and its side effects. The incidence of all side effects of grade 3 or 4 was significantly higher in the $\mathrm{SMI}^{\mathrm{Low}}$ group than in the $\mathrm{SMI}^{\text {High }}$ group $(P=0.028)$. The incidence of grade 3 or 4 gastrointestinal toxicity was 


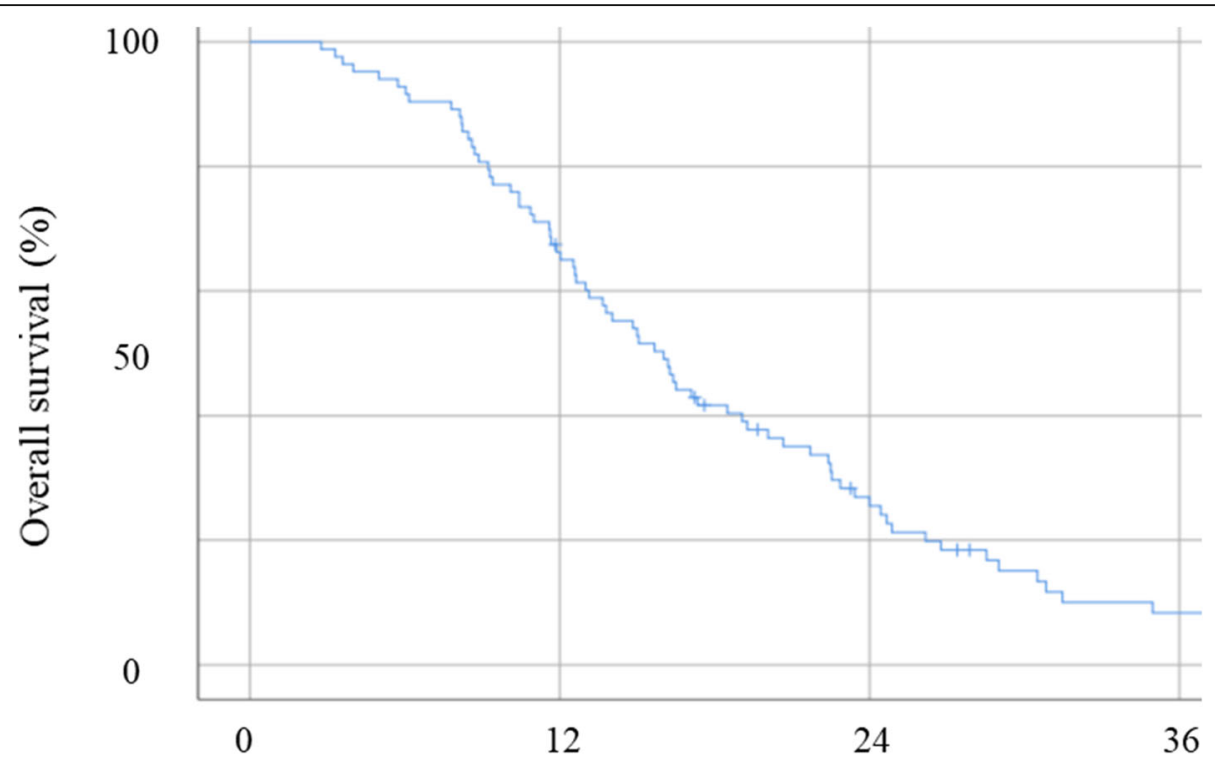

Times (month)

Fig. 2 Overall survival curves in patients with unresectable gastric cancer. Abbreviations: UGC, unresectable gastric cancer

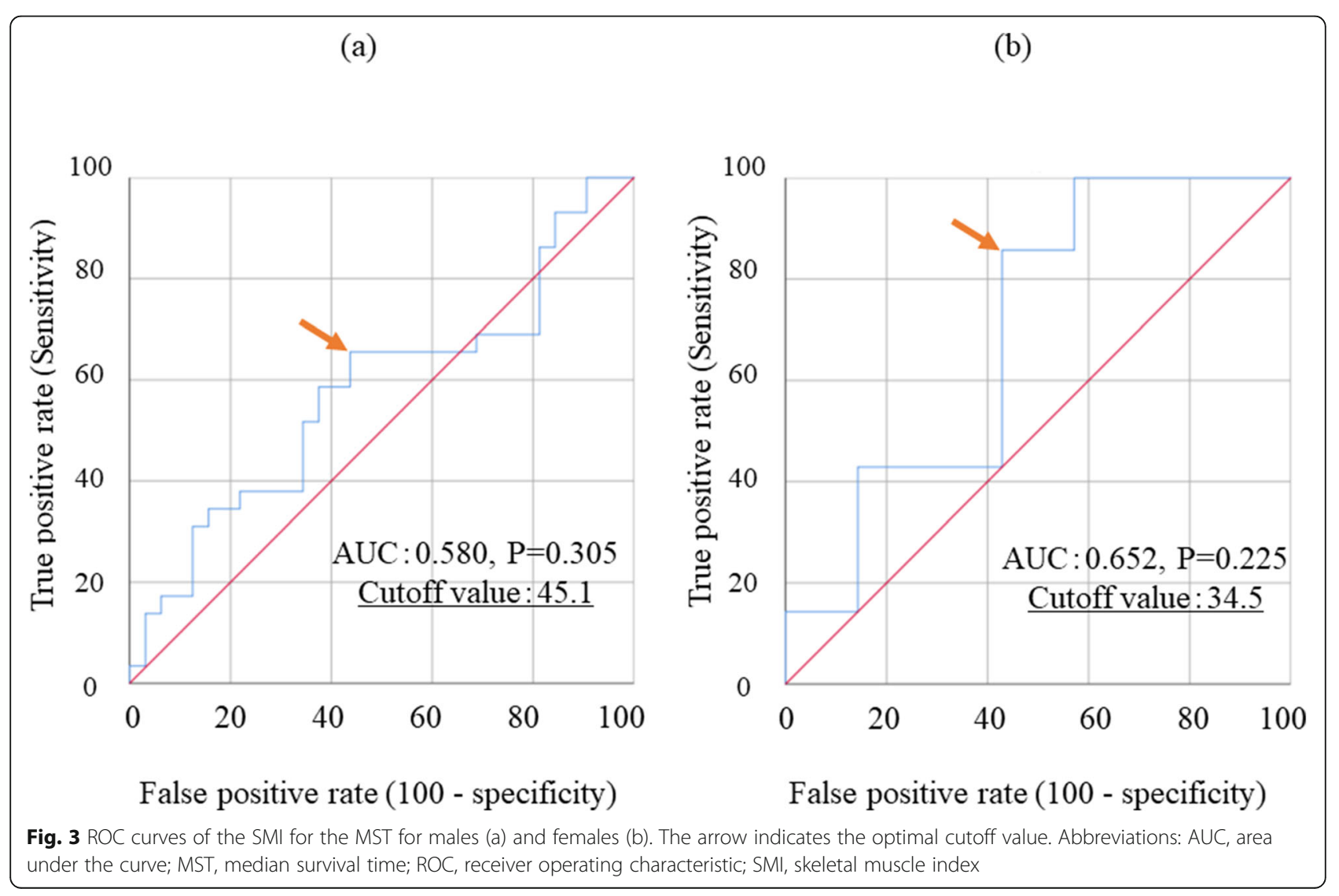




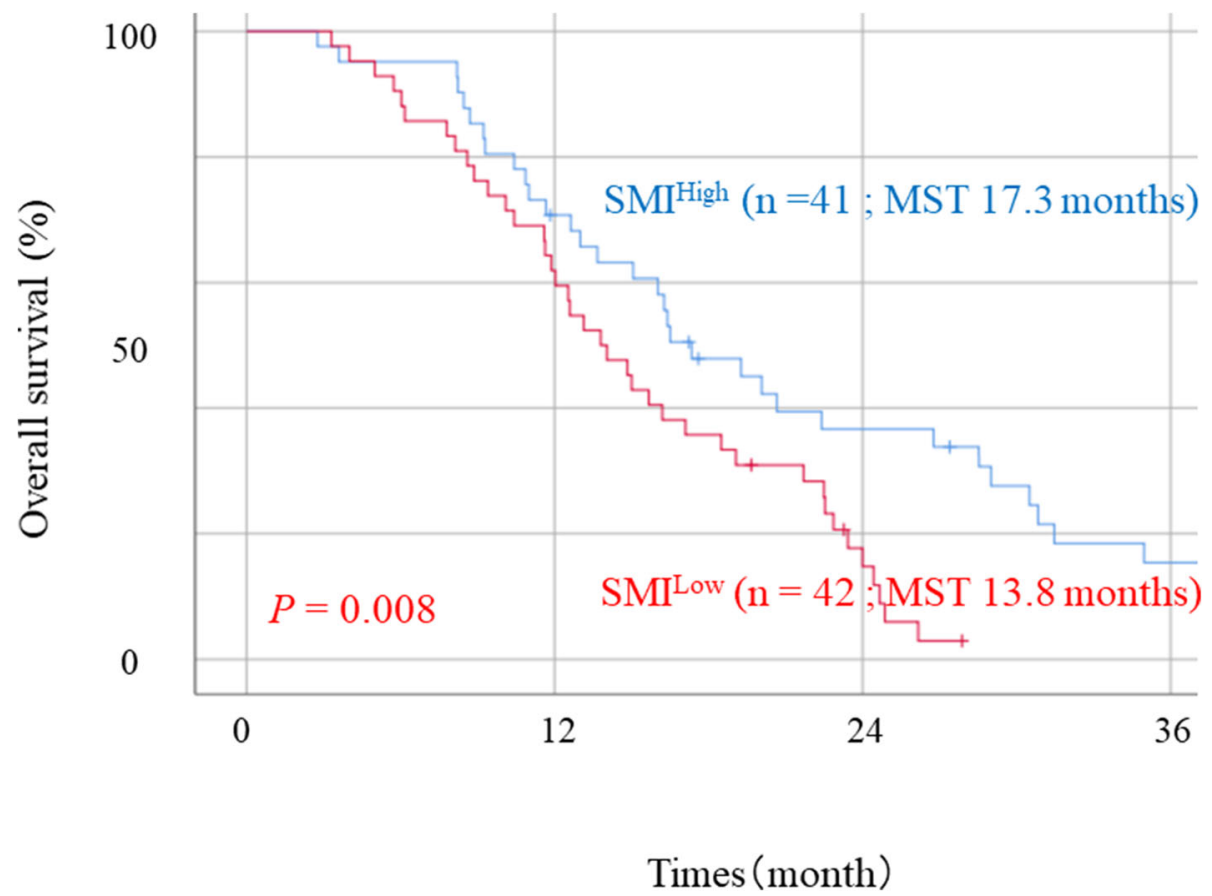

Fig. 4 Overall survival curves according to skeletal muscle mass index in patients with unresectable gastric cancer. Abbreviations: MST, median survival time; $\mathrm{SMI}^{\text {High }}$, high skeletal muscle mass index; $\mathrm{SML}^{\mathrm{Low}}$, low skeletal muscle mass index; UGC, unresectable gastric cancer

significantly higher in the $\mathrm{SMI}^{\mathrm{Low}}$ group than in the $\mathrm{SMI}^{\text {High }}$ group $(P=0.039)$. There were no significant differences in terms of neutropenia, anemia, thrombocytopenia, and FN.

\section{Response to first line chemotherapy}

In this study, $1(1.2 \%)$ patient achieved a complete response, $21(25.3 \%)$ achieved a partial response, and 35 (42.2\%) achieved stable disease, with the remaining 26 patients experiencing progressive disease (PD) (31.3\%).
The objective response rate (ORR) and disease control rate (DCR) were $26.5 \%$ (22 of 83 patients) and $68.7 \%$ (57 of 83 patients), respectively (Table 5 ). No significant differences were observed regarding ORR and DCR between the $\mathrm{SMI}^{\mathrm{High}}$ and $\mathrm{SMI}^{\mathrm{Low}}$ group.

\section{Relationships of nutritional and inflammatory factors with} SMI

Table 6 shows the relationships between various nutrition- and inflammation-based prognostic scores and

Table 2 First-line chemotherapy for patients with UGC with SMI ${ }^{\text {High }}$ and SMI ${ }^{\text {Low }}$

\begin{tabular}{lll}
\hline & $\mathbf{S M I}^{\text {High }}(\mathbf{n}=\mathbf{4 1})$ & $\mathbf{S M I}^{\text {Low }} \mathbf{( n = 4 2 )}$ \\
\hline Monotherapy & & $\mathbf{P}$ value \\
S-1 & $4(9.8)$ & 9.144 \\
Combined chemotherapy & $37(90.2)$ & $33(78.6)$ \\
S-1 + cisplatin & 6 & 13 \\
Combined S-1 + paclitaxel + intraperitoneally infused paclitaxel & 9 & 6 \\
S-1 + oxaliplatin & 8 & 5 \\
S-1 + docetaxel & 8 & 2 \\
Capecitabine + oxaliplatin & 2 & 3 \\
Capecitabine + cisplatin & 1 & 2 \\
Capecitabine + trastuzumab & 2 & 1 \\
S-1 + cisplatin + docetaxel & 1 & 1 \\
\hline
\end{tabular}


Table 3 The details of the side effects of each regimen used in first-line chemotherapy

\begin{tabular}{|c|c|c|c|c|c|c|c|c|c|c|c|c|c|c|c|c|c|c|c|c|c|c|c|c|c|c|c|c|c|}
\hline & \multirow{2}{*}{\multicolumn{4}{|c|}{ Neutropenia }} & \multirow{2}{*}{\multicolumn{4}{|c|}{ Anemia }} & \multirow{2}{*}{\multicolumn{4}{|c|}{ Thrombocytopenia }} & \multicolumn{16}{|c|}{ Gastrointestinal toxicity } & \\
\hline & & & & & & & & & & & & & \multirow{2}{*}{\multicolumn{4}{|c|}{$\begin{array}{l}\text { Nausia/ } \\
\text { Vomitting } \\
\text { grade }\end{array}$}} & \multirow{2}{*}{\multicolumn{4}{|c|}{$\begin{array}{l}\text { Diarrea } \\
\text { grade }\end{array}$}} & \multirow{2}{*}{\multicolumn{4}{|c|}{$\begin{array}{l}\text { Constipation } \\
\text { grade }\end{array}$}} & \multirow{2}{*}{\multicolumn{3}{|c|}{$\begin{array}{l}\text { Mucositis } \\
\text { grade }\end{array}$}} & & \\
\hline & & ade & & & & ade & & & gra & & & & & & & & & & & & & & & & & & & & \\
\hline & 1 & 2 & 3 & 4 & 1 & 2 & 3 & 4 & 1 & 2 & 3 & 4 & 1 & 2 & 3 & 4 & 1 & 2 & 3 & 4 & 1 & 2 & 3 & 4 & 1 & 2 & 3 & & \\
\hline$S-1(n=13)$ & 2 & 2 & 1 & 0 & 2 & 2 & 0 & 0 & 1 & 1 & 0 & 0 & 3 & 2 & 1 & 0 & 2 & 0 & 3 & 0 & 2 & 0 & 0 & 0 & 2 & 0 & 0 & 0 & 0 \\
\hline S- $1+$ cisplatin $(n=19)$ & 5 & 2 & 2 & 3 & 4 & 2 & 0 & 0 & 4 & 2 & 0 & 1 & 5 & 4 & 2 & 0 & 4 & 2 & 0 & 0 & 4 & 0 & 0 & 0 & 1 & 2 & 0 & 0 & 2 \\
\hline $\mathbb{I P}(n=15)$ & 2 & 1 & 3 & 2 & 1 & 1 & 0 & 0 & 2 & 1 & 0 & 0 & 2 & 2 & 0 & 0 & 1 & 1 & 1 & 0 & 3 & 0 & 0 & 0 & 1 & 1 & 0 & 0 & 1 \\
\hline S-1 + oxaliplatin $(n=13)$ & 4 & 2 & 1 & 0 & 3 & 2 & 1 & 0 & 1 & 4 & 0 & 0 & 4 & 2 & 0 & 0 & 2 & 2 & 1 & 0 & 2 & 0 & 0 & 0 & 1 & 2 & 0 & 0 & 0 \\
\hline S-1 + docetaxel $(n=10)$ & 2 & 1 & 0 & 1 & 3 & 1 & 0 & 0 & 2 & 0 & 0 & 0 & 3 & 2 & 1 & 0 & 1 & 1 & 1 & 0 & 2 & 0 & 0 & 0 & 2 & 1 & 0 & 0 & 0 \\
\hline Capecitabine + oxaliplatin $(n=5)$ & 1 & 1 & 0 & 1 & 1 & 0 & 0 & 0 & 1 & 0 & 1 & 0 & 1 & 1 & 1 & 0 & 1 & 0 & 0 & 0 & 1 & 0 & 0 & 0 & 0 & 1 & 0 & 0 & 1 \\
\hline Capecitabine + cisplatin $(\mathrm{n}=3)$ & 2 & 0 & 0 & 0 & 1 & 0 & 0 & 0 & 1 & 0 & 1 & 0 & 1 & 0 & 1 & 0 & 0 & 0 & 0 & 0 & 1 & 0 & 0 & 0 & 1 & 0 & 0 & 0 & 0 \\
\hline Capecitabine + trastuzumab $(n=3)$ & 0 & 0 & 0 & 0 & 0 & 0 & 0 & 0 & 0 & 0 & 0 & 0 & 1 & 0 & 1 & 0 & 0 & 0 & 0 & 0 & 0 & 0 & 0 & 0 & 0 & 0 & 0 & 0 & 0 \\
\hline S-1 + cisplatin + docetaxel $(n=2)$ & 0 & 1 & 1 & 0 & 1 & 0 & 0 & 0 & 1 & 0 & 0 & 0 & 2 & 0 & 0 & 0 & 1 & 1 & 0 & 0 & 1 & 0 & 0 & 0 & 0 & 1 & 0 & 0 & 0 \\
\hline
\end{tabular}

Data are presented as number of patients

FN, febrile neutropenia; IP, Combined S-1 + paclitaxel + intraperitoneally infused paclitaxel

SMI in patients with UGC. NLR was significantly higher in patients with $\mathrm{SMI}^{\mathrm{Low}}$ than those with $\mathrm{SMI}^{\mathrm{High}} \cdot(p=$ 0.047). However, there were no significant differences between the two groups regarding CRP, albumin, PNI, CAR, PLR, CEA, and CA19-9.

\section{Univariate and multivariate analyses of patients with UGC}

We performed univariate analysis of the clinicopathological factors considered prognostic for OS in patients with UGC. In the univariate analysis, ECOG PS, SMI, histological type, lines of chemotherapy ( 3rd line), and NLR were identified as prognostic indicators (Table 7). In the multivariate analysis, we included significant parameters that were identified in the univariate analysis. The multivariate analysis revealed that SMI, NLR, and lines of chemother$\operatorname{apy}(\geqq 3$ rd line $)$ were independent prognostic factors (Table 7).

Table 4 The incidence of grade 3 or 4 side effects in patients with UGC with SMI ${ }^{\text {High }}$ and SMI ${ }^{\text {Low }}$

\begin{tabular}{|c|c|c|c|}
\hline & $\mathrm{SMI}^{\text {High }}(\mathrm{n}=41)$ & SMI $^{\text {Low }}(n=42)$ & $P$ value \\
\hline All side effects of grade 3 or 4 & & & 0.028 \\
\hline Positive & $10(24.3)$ & $20(47.6)$ & \\
\hline Negative & $31(75.7)$ & $22(52.4)$ & \\
\hline Neutropenia of grade 3 or 4 & & & 0.421 \\
\hline Positive & $6(14.6)$ & $9(21.4)$ & \\
\hline Negative & $35(85.4)$ & $33(78.6)$ & \\
\hline Anemia of grade 3 or 4 & & & 0.309 \\
\hline Positive & $1(2.4)$ & 0 & \\
\hline Negative & $40(97.6)$ & 42 & \\
\hline Thrombocytopenia of grade 3 or 4 & & & 0.081 \\
\hline Positive & 0 & $3(7.1)$ & \\
\hline Negative & 41 & $39(92.9)$ & \\
\hline Gastrointestinal toxicity & & & 0.039 \\
\hline Positive & $3(7.3)$ & $10(23.8)$ & \\
\hline Negative & $38(92.7)$ & $32(76.2)$ & \\
\hline FN & & & 0.980 \\
\hline Positive & $2(4.9)$ & $2(4.8)$ & \\
\hline Negative & $39(95.1)$ & $40(95.2)$ & \\
\hline
\end{tabular}

Data are presented as number (percentage) of patients

FN, febrile neutropenia; SMI ${ }^{\text {High }}$, high skeletal muscle mass; SMI ${ }^{\text {Low }}$, low skeletal muscle mass; UGC, unresectable gastric cancer; SMI, skeletal muscle mass 
Table 5 Responses to first line chemotherapy

\begin{tabular}{llll}
\hline & All patients $(\mathbf{n}=\mathbf{8 3})$ & $\mathbf{S M I}^{\text {High }}(\mathbf{n}=\mathbf{4 1})$ & $\mathbf{S M I}^{\text {Low }}(\mathbf{n}=\mathbf{4 2})$ \\
\hline $\begin{array}{lll}\text { Best overall response } \\
\text { CR }\end{array}$ & & \\
PR & $(1.2)$ & $1(2.4)$ & 0 \\
SD & $21(25.3)$ & $9(22.0)$ & $12(28.6)$ \\
PD & $35(42.2)$ & $21(51.2)$ & $14(33.3)$ \\
ORR & $26(31.3)$ & $10(24.4)$ & $16(38.1)$ \\
DCR & $22(26.5)$ & $10(24.4)$ & $12(28.6)$ \\
\hline
\end{tabular}

Data are presented as number (percentage) of patients

$\mathrm{CR}$, complete response; $\mathrm{PR}$, partial response; $\mathrm{SD}$, stable disease; $\mathrm{PD}$, progressive disease; ORR objective response rate, $(\mathrm{CR}+\mathrm{PR}) * 100 /$ total cases; $\mathrm{DCR}$, disease control rate, $(C R+P R+S D) * 100 /$ total cases, SMI ${ }^{\text {High }}$, high skeletal muscle mass; SMl ${ }^{\text {Low }}$, low skeletal muscle mass; UGC, unresectable gastric cancer

\section{Discussion}

In this study, the SMI ${ }^{\text {Low }}$ group had significantly more grade 3 or 4 side effects and were related to high NLR. The $\mathrm{SMI}^{\mathrm{Low}}$ group had significantly less conversion to third-line chemotherapy than the $\mathrm{SMI}^{\mathrm{High}}$ group and had a significantly worse prognosis than the $\mathrm{SMI}^{\text {High }}$ group.

In this study, the SMI ${ }^{\text {Low }}$ group had a significantly worse prognosis than the SMI ${ }^{\text {High }}$ group. Sarcopenia has been reported to indicate a poor prognosis in several cancers, including gastric cancer. Kamarajah et al. described that a meta-analysis of nine studies reporting OS after gastrectomy identified significantly worse survival in patients with preoperative sarcopenia [25]. However, there are few studies reporting the prognostic significance of sarcopenia in patients with UGC. Kouzu et al. retrospectively analyzed the prognostic significance of sarcopenia in 67 patients who experienced gastric cancer recurrence and found that sarcopenia was an independent negative prognostic factor [26]. This study had results similar to our results; however, the reason for poor

Table 6 Nutrition- and inflammation-based markers of patients with SMI High and SMI ${ }^{\text {Low }}$ UGC

\begin{tabular}{llll}
\hline & $\mathbf{S M I}^{\text {High }}(\mathbf{n}=\mathbf{4 1})$ & $\mathbf{S M I}^{\text {Low }}(\mathbf{n}=\mathbf{4 2})$ & P value \\
\hline CRP & $0.789 \pm 0.928$ & $1.273 \pm 2.731$ & 0.245 \\
Albumin & $3.7 \pm 0.5$ & $3.5 \pm 0.7$ & 0.296 \\
PNI & $45.05 \pm 5.73$ & $42.4 \pm 8.7$ & 0.108 \\
NLR & $2.567 \pm 1.081$ & $4.110 \pm 4.560$ & 0.047 \\
CAR & $0.220 \pm 0.255$ & $0.514 \pm 1.264$ & 0.308 \\
PLR & $189.0 \pm 103.7$ & $224.9 \pm 135.2$ & 0.226 \\
CEA & $18.3 \pm 49.1$ & $16.7 \pm 38.4$ & 0.604 \\
CA19-9 & $334.9 \pm 1198.2$ & $111.6 \pm 416.2$ & 0.610
\end{tabular}

Data are presented as the mean \pm standard deviation or number (percentage) of patients

CA19-9, carbohydrate antigen; CEA, carcinoembryonic antigen; CRP, C-reactive protein; CAR, C-reactive protein-to-albumin ratio; NLR, neutrophil to lymphocyte ratio; PLR, platelet to lymphocyte ratio; PNI, the prognostic nutritional index; $\mathrm{SMI}^{\text {High }}$, high skeletal muscle mass; $\mathrm{SMI}^{\text {Low }}$, low skeletal muscle mass; UGC, unresectable gastric cancer prognosis with sarcopenia was unclear in patients with UGC. In patients with UGC, palliative chemotherapy was standard therapy to improve the survival rate. However, we often saw that once a clinical response had been achieved by chemotherapy, the effect might not be sustained, and the chemotherapy regimen had to be changed. It is important to use all available drugs to increase the survival rate of patients with UGC, and the importance of third-line treatment in gastric cancer has been reported $[27,28]$. In this study, the number of patients who received third-line chemotherapy was significantly higher in the $\mathrm{SMI}^{\mathrm{High}}$ group than in the SMI ${ }^{\text {Low }}$ group. One potential reason for poor prognosis in patients with low SMM might be the low rate of receiving third-line chemotherapy, as in the SMI ${ }^{\mathrm{Low}}$ group in our study.

In this study, the $\mathrm{SMI}^{\mathrm{Low}}$ group had significantly more grade 3 or 4 side effects than the $\mathrm{SMI}^{\mathrm{High}}$ group, and the result was similar to results reported by Kurk et al. [29] They retrospectively examined 414 patients with metastatic colorectal cancer treated with capecitabine-based chemotherapy and reported that sarcopenia and/or muscle loss was associated with an increased risk of dose-limiting toxicities. Likewise, Matsuura et al. reported that low SMM was associated with an increased risk of chemotherapy-induced toxicity [30]. They retrospectively examined 41 patients with gastric cancer undergoing neoadjuvant chemotherapy and revealed that low SMM was the only factor significantly associated with severe diarrhea in univariate and multivariate analyses. These results showed that low SMM was related to the high-grade toxicity of chemotherapy. However, the mechanism that associated low SMM with toxicity was unclear. This may be due to the clearance of 5-FU. 5-FU, the main drug for gastric cancer, is hydrophilic but widely distributed due to active transport [31]. This drug undergoes extensive metabolism primarily via dihydropyrimidine dehydrogenase [31], and variants of dihydropyrimidine dehydrogenase have been associated with an increased risk of 5-FU toxicity [32]. It is reported that patients with high SMM have increased 5-FU clearance 
Table 7 Univariate and multivariate analyses of prognostic factors for OS in patients with UGC

\begin{tabular}{|c|c|c|c|c|c|c|}
\hline & \multicolumn{3}{|c|}{ Univariate analysis } & \multicolumn{3}{|c|}{ Multivariate analysis } \\
\hline & Hazard ratio & $95 \% \mathrm{Cl}$ & $P$ value & Hazard ratio & $95 \% \mathrm{Cl}$ & $P$ value \\
\hline Age $(\geqq 75$ vs $<75)$ & 1.148 & $0.680-1.938$ & 0.605 & & & \\
\hline Gender (Female vs Male) & 1.224 & $0.718-2.086$ & 0.457 & & & \\
\hline ECOG PS (1,2 vs 0) & 2.203 & $1.372-3.537$ & 0.001 & 1.355 & $0.786-2.337$ & 0.274 \\
\hline $\mathrm{BMI}(<18.0$ vs $\geqq 18.0)$ & 1.401 & $0.864-2.271$ & 0.172 & & & \\
\hline SMI (Low vs High) & 1.964 & $1.183-3.252$ & 0.009 & 1.886 & $1.156-3.077$ & 0.011 \\
\hline Histologic type (Differentiated vs Undifferentiated) & 1.775 & $1.087-2.897$ & 0.022 & 1.619 & $0.990-2.648$ & 0.061 \\
\hline Peritoneum metastasis (Present vs Absent) & 1.138 & $0.698-1.854$ & 0.605 & & & \\
\hline Lymph node metastasis (Present vs Absent) & 1.019 & $0.642-1.618$ & 0.936 & & & \\
\hline Hematogenous metastasis (Present vs Absent) & 1.101 & $0.675-1.793$ & 0.702 & & & \\
\hline Lines of chemotherapy ( $\geqq 2$ nd line vs $<2$ nd line) & 0.958 & $0.513-1.789$ & 0.893 & & & \\
\hline Lines of chemotherapy ( $\geqq 3$ rd line vs $<3$ rd line) & 0.408 & $0.253-0.659$ & $<0.001$ & 0.420 & $0.248-0.712$ & $<0.001$ \\
\hline $\mathrm{PNI}(<43.9$ vs $\geqq 43.9)$ & 1.589 & $0.991-2.813$ & 0.052 & & & \\
\hline $\operatorname{NLR}(\geqq 2.881$ vs $<2.881)$ & 2.071 & $1.297-3.307$ & 0.002 & 2.167 & $1.325-3.544$ & 0.002 \\
\hline CAR $(\geqq 0.077$ vs $<0.077)$ & 1.361 & $0.854-2.171$ & 0.195 & & & \\
\hline PLR $(\geqq 267$ vs $<267)$ & 1.490 & $0.885-2.510$ & 0.134 & & & \\
\hline
\end{tabular}

BMI, body mass index; CAR, C-reactive protein-to-albumin ratio; ECOG PS, Eastern Cooperative Oncology Group performance status; NLR, neutrophil to lymphocyte ratio; OS, overall survival; PLR, platelet to lymphocyte ratio; PNI, the prognostic nutritional index; SMI, skeletal musclemass; UGC, unresectable gastric cancer

[33]. These findings suggest that decreased clearance of 5-FU due to low SMM may be related to increased side effects. Another possible reason is that the dose of chemotherapy is highly dependent on the patient's height and weight, and changes in body composition may not be taken into account $[33,34]$. Patients with sarcopenia tend to receive more chemotherapeutic agents with relatively low lean body mass, and as a result, they are more likely to suffer toxicity. This suggests that there are still opportunities for improvement in current dosage calculation methods. There is also a need for research on the optimal adjustment method for sarcopenia when prescribing chemotherapeutic agents.

In this study, NLR was an independent prognostic factor, and it was significantly higher in patients with SMILow than those with $\mathrm{SMI}^{\mathrm{High}}$. These results were similar to results reported by Feliciano et al. [35] They retrospectively examined 2470 patients with colorectal cancer and found that NLR was associated with sarcopenia, and high NLR independently predicted poor OS. Kim et al. also reported that sarcopenia was associated with higher NLR in 186 patients with small cell lung cancer [36]. These results suggested that high NLR was related to poor survival. High NLR reflected a decreased peripheral lymphocyte count or an elevated peripheral neutrophil count. Low preoperative lymphocyte count is reportedly related to poor survival in several types of cancer [37, 38]. Neutrophils are important components of several inflammatory responses, including interleukin-6 (IL-6) [39], which has dual tumor development and metastasis roles. A high neutrophil count is related to a poor prognosis [40]. Sarcopenia is associated with cytokines, including IL-6 [41]. These findings suggest that high NLR is related to poor prognosis and indicate that there may be a link between NLR and sarcopenia.

This study has several limitations. First, we have conducted this retrospective study with patients from a single institution, and the number of patients is not large. Second, the first-line chemotherapy is chosen based on 5-FU, but this was not consistent. This is a long-term study and the guidelines have changed over time. Chemotherapy is administered per the guidelines in place at the time of treatment. Third, the optimal cutoff SMI value has not been determined in patients with UGC. Fourth, we have enrolled patients with both recurrent gastric cancer and advanced gastric cancer. Fifth, information regarding inflammatory cytokines such as IL-6 is not available because of the retrospective design. Therefore, well-designed, randomized, prospective studies with larger populations are needed to confirm these findings.

In conclusion, patients with UGC with low SMI have significantly more grade 3 or 4 side effects than those with high SMI, and SMI is a useful prognostic marker of UGC. In patients with UGC with low SMI, the side effects of chemotherapy, particularly those related to gastrointestinal toxicity, should be carefully managed in subsequent treatment.

\section{Abbreviations}

BMI: body mass index; CA19-9: carbohydrate antigen; CEA: carcinoembryonic antigen; CRP: C-reactive protein; CAR: C-reactive protein-to-albumin ratio; ECOG PS: eastern cooperative oncology group performance status; 
FN: febrile neutropenia; NLR: neutrophil-to-lymphocyte ratio; OS: overall survival; PLR: platelet-to-lymphocyte ratio; PNI: the prognostic nutritional index; SMI: skeletal muscle mass index; SMI ${ }^{\text {High }}$ : high skeletal muscle mass; SMl ${ }^{\text {Low: }}$ low skeletal muscle mass; SMM: skeletal muscle mass;

UGC: Unresectable gastric cancer; CT: Computed tomography; MST: Median survival time

\section{Acknowledgments}

We thank Enago Group for editing a draft of this manuscript.

\section{Authors' contributions}

TM contributed to the conception and design of the study. HS, WM, YS, KM, MM, YM, TH, and KK contributed to the quality control of data and algorithms. MY, NT, ST, TS, and TH contributed to the data analysis and interpretation. TM contributed to the manuscript preparation and editing. YF contributed to the manuscript review and final approval of the article. All authors read and approved the final manuscript.

\section{Funding}

The authors have no financial support to declare.

\section{Availability of data and materials}

The datasets used and analyzed during the current study are available from the corresponding author on reasonable request.

\section{Declarations}

\section{Ethics approval and consent to participate}

This study was conducted in compliance with the Declaration of Helsinki and guidelines on Good Clinical Practice and was conducted with the approval of the institutional review board of our institution (Tottori University, number 20A243), and the informed consent requirement was waived.

\section{Consent for publication}

Not applicable.

\section{Competing interests}

The authors declare that they have no competing interests.

\section{Author details}

${ }^{1}$ Department of Surgery, Division of Gastrointestinal and Pediatric Surgery, School of Medicine, Tottori University Faculty of Medicine, 36-1 Nishi-cho, Yonago 683-8504, Japan. ²Department of Surgery, Japanese Red Cross Tottori Hospital, 117 Shotoku-cho, Tottori 680-8517, Japan.

Received: 16 July 2021 Accepted: 2 November 2021

Published online: 13 November 2021

\section{References}

1. Bray F, Ferlay J, Soerjomataram I, Siegel RL, Torre LA, Jemal A. Global cancer statistics 2018: GLOBOCAN estimates of incidence and mortality worldwide for 36 cancers in 185 countries. CA Cancer J Clin. 2018;68(6):394-424. https://doi.org/10.3322/caac.21492.

2. Zou ZH, Zhao LY, Mou TY, Hu YF, Yu J, Liu H, et al. Laparoscopic vs open D2 gastrectomy for locally advanced gastric cancer: a meta-analysis. World J Gastroenterol. 2014;20(44):16750-64. https://doi.org/10.3748/wjg.v20.i44.1 6750.

3. Digklia A, Wagner AD. Advanced gastric cancer: current treatment landscape and future perspectives. World J Gastroenterol. 2016;22(8):240314. https://doi.org/10.3748/wjg.v22.i8.2403.

4. Li Z, Shan F, Ying X, Zhang Y, E JY, Wang Y, Ren H, Su X, Ji J: assessment of laparoscopic distal gastrectomy after neoadjuvant chemotherapy for locally advanced gastric Cancer: a randomized clinical trial. JAMA Surg 2019, 154(12):1093-1101, DOI: https://doi.org/10.1001/jamasurg.2019.3473.

5. Guo X, Zhao F, Ma X, Shen G, Ren D, Zheng F, et al. A comparison between triplet and doublet chemotherapy in improving the survival of patients with advanced gastric cancer: a systematic review and meta-analysis. BMC Cancer. 2019;19(1):1125. https://doi.org/10.1186/s12885-019-6294-9.

6. Koizumi W, Narahara H, Hara T, Takagane A, Akiya T, Takagi M, et al. S-1 plus cisplatin versus S-1 alone for first-line treatment of advanced gastric cancer
(SPIRITS trial): a phase III trial. Lancet Oncol. 2008;9(3):215-21. https://doi. org/10.1016/\$1470-2045(08)70035-4.

7. Japanese gastric cancer treatment guidelines 2018 (5th edition). Gastric Cancer 2021, 24(1):1-21, DOl: https://doi.org/10.1007/s10120-020-01042-y.

8. Bang YJ, Van Cutsem E, Feyereislova A, Chung HC, Shen L, Sawaki A, et al. Trastuzumab in combination with chemotherapy versus chemotherapy alone for treatment of HER2-positive advanced gastric or gastrooesophageal junction cancer (ToGA): a phase 3, open-label, randomised controlled trial. Lancet. 2010;376(9742):687-97. https://doi.org/10.1016/S014 0-6736(10)61121-X.

9. Kanazawa Y, Yamada T, Kakinuma D, Matsuno K, Ando F, Fujita I, et al. Skeletal muscle mass depletion after gastrectomy negatively affects the prognosis of patients with gastric Cancer. Anticancer Res. 2020;40(8):4271-9. https://doi.org/10.21873/anticanres.14429.

10. Kuwada K, Kuroda S, Kikuchi S, Yoshida R, Nishizaki M, Kagawa S, et al. Clinical impact of sarcopenia on gastric Cancer. Anticancer Res. 2019;39(5): 2241-9. https://doi.org/10.21873/anticanres.13340.

11. Antoun S, Borget I, Lanoy E. Impact of sarcopenia on the prognosis and treatment toxicities in patients diagnosed with cancer. Curr Opin Support Palliat Care. 2013;7(4):383-9. https://doi.org/10.1097/SPC.0000000000000011.

12. Shachar SS, Deal AM, Weinberg M, Nyrop KA, Williams GR, Nishijima TF, et al. Skeletal muscle measures as predictors of toxicity, hospitalization, and survival in patients with metastatic breast Cancer receiving Taxane-based chemotherapy. Clin Cancer Res. 2017;23(3):658-65. https://doi.org/10.1158/1 078-0432.CCR-16-0940.

13. Saito H, Kono Y, Murakami $Y$, Shishido $Y$, Kuroda H, Matsunaga $T$, et al. Prognostic significance of platelet-based inflammatory indicators in patients with gastric Cancer. World J Surg. 2018;42(8):2542-50. https://doi.org/10.1 007/s00268-018-4527-8.

14. Chen JH, Zhai ET, Yuan YJ, Wu KM, Xu JB, Peng JJ, et al. Systemic immuneinflammation index for predicting prognosis of colorectal cancer. World J Gastroenterol. 2017;23(34):6261-72. https://doi.org/10.3748/wjg.v23.i34.6261.

15. Harada K, Ida S, Baba Y, Ishimoto T, Kosumi K, Tokunaga R, et al. Prognostic and clinical impact of sarcopenia in esophageal squamous cell carcinoma. Dis Esophagus. 2016;29(6):627-33. https://doi.org/10.1111/dote.12381.

16. Mitsiopoulos N, Baumgartner RN, Heymsfield SB, Lyons W, Gallagher D, Ross R. Cadaver validation of skeletal muscle measurement by magnetic resonance imaging and computerized tomography. J Appl Physiol (1985). 1998;85(1):115-22

17. Shen W, Punyanitya M, Wang Z, Gallagher D, St-Onge MP, Albu J, et al. Total body skeletal muscle and adipose tissue volumes: estimation from a single abdominal cross-sectional image. J Appl Physiol (1985). 2004;97(6):2333-8.

18. Martin L, Birdsell L, Macdonald N, Reiman T, Clandinin MT, McCargar L, et al. Cancer cachexia in the age of obesity: skeletal muscle depletion is a powerful prognostic factor, independent of body mass index. J Clin Oncol. 2013;31(12):1539-47. https://doi.org/10.1200/JCO.2012.45.2722.

19. Japanese classification of gastric carcinoma: 3rd English edition. Gastric Cancer. 2011;14(2):113-23. https://doi.org/10.1007/s10120-011-0042-4.

20. Japanese gastric cancer treatment guidelines 2014 (ver. 4). Gastric Cancer 2017, 20(1):1-19, DOl: https://doi.org/10.1007/s10120-016-0622-4.

21. Basch E, Reeve BB, Mitchell SA, Clauser SB, Minasian LM, Dueck AC, et al. Development of the National Cancer Institute's patient-reported outcomes version of the common terminology criteria for adverse events (PRO-CTCA E). J Natl Cancer Inst. 2014;106(9). https://doi.org/10.1093/jnci/dju244.

22. Kinoshita A, Onoda H, Imai N, Iwaku A, Oishi M, Tanaka K, et al. The Creactive protein/albumin ratio, a novel inflammation-based prognostic score, predicts outcomes in patients with hepatocellular carcinoma. Ann Surg Oncol. 2015;22(3):803-10. https://doi.org/10.1245/s10434-014-4048-0.

23. Saito H, Kono $Y$, Murakami $Y$, Shishido $Y$, Kuroda H, Matsunaga T, et al. Prognostic significance of the preoperative ratio of $C$-reactive protein to albumin and neutrophil-lymphocyte ratio in gastric Cancer patients. World J Surg. 2018;42(6):1819-25. https://doi.org/10.1007/s00268-017-4400-1.

24. Onodera T, Goseki N. Kosaki G: [prognostic nutritional index in gastrointestinal surgery of malnourished cancer patients]. Nihon Geka Gakkai Zasshi. 1984;85(9):1001-5.

25. Kamarajah SK, Bundred J, Tan BHL. Body composition assessment and sarcopenia in patients with gastric cancer: a systematic review and metaanalysis. Gastric Cancer. 2019;22(1):10-22. https://doi.org/10.1007/s10120-01 8-0882-2.

26. Kouzu K, Tsujimoto H, Sugasawa H, Ishibashi Y, Itazaki Y, Tsuchiya S, et al. Impact of postoperative reduced skeletal muscle on prognosis after 
recurrence in gastric cancer. Mol Clin Oncol. 2021;14(1):3. https://doi.org/1 0.3892/mco.2020.2165.

27. Ueno M, Doi A, Sunami T, Takayama H, Mouri H, Mizuno M. Delivery rate of patients with advanced gastric cancer to third-line chemotherapy and those patients' characteristics: an analysis in real-world setting. J Gastrointest Oncol. 2019;10(5):957-64. https://doi.org/10.21037/jgo.2019.05.07.

28. Rizzo A, Mollica V, Ricci AD, Maggio I, Massucci M, Rojas Limpe FL, et al. Third- and later-line treatment in advanced or metastatic gastric cancer: a systematic review and meta-analysis. Future Oncol. 2020;16(2):4409-18. https://doi.org/10.2217/fon-2019-0429.

29. Kurk S, Peeters P, Stellato R, Dorresteijn B, de Jong P, Jourdan M, et al. Skeletal muscle mass loss and dose-limiting toxicities in metastatic colorectal cancer patients. J Cachexia Sarcopenia Muscle. 2019;10(4):803-13. https://doi.org/10.1002/jcsm.12436.

30. Matsuura N, Motoori M, Fujitani K, Nishizawa Y, Komatsu H, Miyazaki Y, et al. Correlation between skeletal muscle mass and adverse events of neoadjuvant chemotherapy in patients with gastric Cancer. Oncology. 2020; 98(1):29-34. https://doi.org/10.1159/000502613

31. Nies AT, Magdy T, Schwab M, Zanger UM. Role of ABC transporters in fluoropyrimidine-based chemotherapy response. Adv Cancer Res. 2015;125: 217-43. https://doi.org/10.1016/bs.acr.2014.10.007.

32. Caudle KE, Thorn CF, Klein TE, Swen JJ, McLeod HL, Diasio RB, et al. Clinical pharmacogenetics implementation consortium guidelines for dihydropyrimidine dehydrogenase genotype and fluoropyrimidine dosing. Clin Pharmacol Ther. 2013;94(6):640-5. https://doi.org/10.1038/clpt.2013.172.

33. Gusella M, Toso S, Ferrazzi E, Ferrari M, Padrini R. Relationships between body composition parameters and fluorouracil pharmacokinetics. Br J Clin Pharmacol. 2002;54(2):131-9. https://doi.org/10.1046/j.1365-2125.2002.01598. $x$.

34. Hopkins JJ, Sawyer MB. A review of body composition and pharmacokinetics in oncology. Expert Rev Clin Pharmacol. 2017;10(9):94756. https://doi.org/10.1080/17512433.2017.1347503.

35. Feliciano EMC, Kroenke CH, Meyerhardt JA, Prado CM, Bradshaw PT, Kwan $\mathrm{ML}$, et al. Association of Systemic Inflammation and Sarcopenia with Survival in nonmetastatic colorectal Cancer: results from the C SCANS study. JAMA Oncol. 2017;3(12):e172319. https://doi.org/10.1001/jamaoncol.201 7.2319.

36. Kim EY, Kim YS, Seo JY, Park I, Ahn HK, Jeong YM, et al. The relationship between sarcopenia and systemic inflammatory response for Cancer Cachexia in small cell lung Cancer. PLoS One. 2016;11(8):e0161125. https:// doi.org/10.1371/journal.pone.0161125.

37. Rho SY, Hwang HK, Chong JU, Yoon DS, Lee WJ, Kang CM. Association of preoperative total lymphocyte count with prognosis in resected left-sided pancreatic cancer. ANZ J Surg. 2019;89(5):503-8. https://doi.org/10.1111/a ns. 15030 .

38. Saroha S, Uzzo RG, Plimack ER, Ruth K, Al-Saleem T. Lymphopenia is an independent predictor of inferior outcome in clear cell renal carcinoma. J Urol. 2013;189(2):454-61. https://doi.org/10.1016/j.juro.2012.09.166.

39. Fridlender ZG, Sun J, Kim S, Kapoor V, Cheng G, Ling L, et al. Polarization of tumor-associated neutrophil phenotype by TGF-beta: "N1" versus "N2" TAN. Cancer Cell. 2009;16(3):183-94. https://doi.org/10.1016/j.ccr.2009.06.017.

40. Terzić J, Grivennikov S, Karin E, Karin M. Inflammation and colon cancer. Gastroenterology. 2010;138(6):2101-2114.e2105.

41. Rong YD, Bian AL, Hu HY, Ma Y, Zhou XZ. Study on relationship between elderly sarcopenia and inflammatory cytokine IL-6, anti-inflammatory cytokine IL-10. BMC Geriatr. 2018;18(1):308. https://doi.org/10.1186/s12877018-1007-9.

\section{Publisher's Note}

Springer Nature remains neutral with regard to jurisdictional claims in published maps and institutional affiliations.

Ready to submit your research? Choose BMC and benefit from:

- fast, convenient online submission

- thorough peer review by experienced researchers in your field

- rapid publication on acceptance

- support for research data, including large and complex data types

- gold Open Access which fosters wider collaboration and increased citations

- maximum visibility for your research: over $100 \mathrm{M}$ website views per year

At BMC, research is always in progress.

Learn more biomedcentral.com/submissions 